\title{
Genetic Variation in Toll-Like Receptor Signalling and the Risk of Inflammatory and Immune Diseases
}

\author{
Sinead C. Corr Luke A.J. O'Neill \\ School of Biochemistry and Immunology, Trinity College Dublin, Dublin, Ireland
}

\section{Key Words}

Toll-like receptor $\cdot$ Genetic variation $\cdot$ MyD88 adapter-like • IRAK4

\begin{abstract}
There has been growing interest in the role of host genetic factors in humans and susceptibility to infectious and inflammatory diseases. Genetic variation in Toll-like receptors (TLRs), key innate immune receptors or their signalling molecules, have been described. Variation in certain TLRs has been linked to disease susceptibility. This genetic variation can result in an altered immune response to pathogenic challenge as well as exorbitant immune activation and inflammation, and thus may influence the pathogenesis or outcome of disease. Examples include variants of TLR4 in sepsis, malaria, inflammatory bowel disease and atherosclerosis; variants in TLR2 in tuberculosis and asthma; a variant in Mal (a key signal for TLR2 and TLR4) in malaria, tuberculosis and systemic lupus erythematosus; and variants in the kinase IRAK4 in pyogenic infections. These associations provide us with a validation for the role of TLRs in human disease, and also suggest possible strategies to limit or boost TLR function in the effort to develop new therapies.
\end{abstract}

Copyright $\odot 2009$ S. Karger AG, Base

\section{KARGER}

Fax +41613061234 E-Mail karger@karger.ch www.karger.com (c) 2009 S. Karger AG, Basel

1662-811X/09/0014-0350\$26.00/0

Accessible online at:

www.karger.com/jin

\section{Introduction}

Toll-like receptors (TLRs) have been identified as key host molecules required for the induction of innate immune responses to various microbial ligands and endogenous host factors released by damaged cells. Much work has been done on the role of TLRs in the host defence response to a variety of pathogens. The responses elicited by TLR signalling have been extensively characterised. Key outputs from TLRs include pro-inflammatory cytokines, such as interleukin-1 $\beta$ (IL-1 $\beta$ ) and tumour necrosis factor, cytokines that promote $\mathrm{T}$ cell differentiation, such as IL-12, anti-viral interferons and chemokines. TLR signalling results in an inflammatory response and also provides important links between innate and adaptive immunity. Based on studies in knockout mice, TLRs have been shown to be key to initiation of innate responses to pathogens. A potential role for TLRs in human diseases came from effects of ligands on human cells and overexpression of TLRs in disease. However, recently, there has been much interest in TLR polymorphisms, and possible associations with altered susceptibility to infectious and inflammatory diseases in humans have been described. The availability of the human genome sequence has enabled a detailed look at variation between individuals, the most common source of variation being single nucleotide polymorphisms

Dr. Sinead C. Cor

Lab 1.1, School of Biochemistry and Immunology

Trinity College Dublin

Lincoln Place, Dublin 1 (Ireland)

Tel. +353 1896 2449, Fax +353 1677 2400, E-Mail corrsinead@gmail.com 


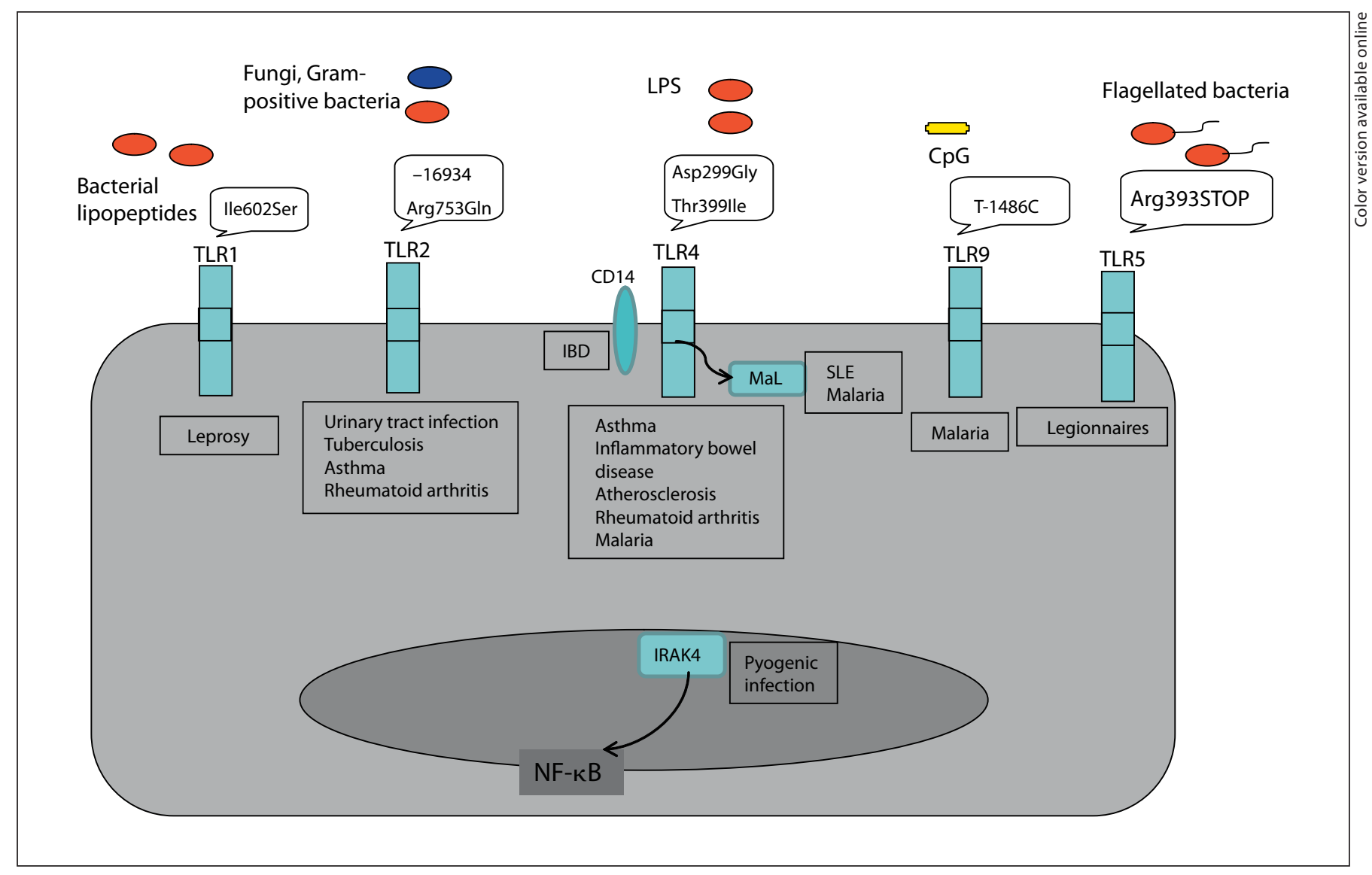

Fig. 1. Genetic associations between TLRs and susceptibility to infectious and inflammatory diseases. Multiple associations have been found between TLRs and susceptibility to certain infectious and inflammatory diseases. The particular variant in each TLR,
CD14, Mal or IRAK4 is shown, and the diseases where associations have been found with each variant are listed underneath. Clear mechanistic explanations for the associations have yet to be provided.
(SNPs). Through amplification of gene coding sequences or exons in groups of people, it has been possible to detect polymorphisms and to ascertain a role in disease susceptibility. Also, the use of gene-targeted mice has provided valuable information about TLR function. While these techniques have begun to shed light on the significance of TLR function and disease, there have been conflicting results and some associations have been difficult to repeat. Discrepancies between association studies may be due to differences in ethnicity, location, environmental factors and exposure to infectious agents. As a result, it has been difficult to confirm a link between certain TLR variants, altered signal transduction and disease susceptibility. In this review, we discuss the possible role of TLRs in the pathogenesis of various human diseases, based on genetic association between
SNPs and TLRs or their signalling molecules. There are now clear examples of such associations that validate certain TLRs in the context of human disease, although some have not been replicated. Figure 1 illustrates the association of SNPs in TLRs or their signalling molecules with human disease.

\section{Inflammatory Bowel Disease}

Inflammatory bowel disease (IBD) refers to chronic inflammatory conditions, mainly Crohn's disease (CD) which affects any part of the gastrointestinal tract from mouth to anus, and ulcerative colitis (UC) which is restricted to the colon and rectum. IBD is characterised by diarrhoea and abdominal pain, and patients may also 
experience fever, fatigue, weight loss, dehydration and malnutrition. Although the exact cause of IBD is unknown, it is believed that a number of factors contribute to susceptibility including environment, diet and possibly genetics. The intestinal flora is also thought to contribute to IBD either by initiating or exacerbating the disease. Host-bacterial interactions and responses mediated by pathogen recognition receptors have been implicated in IBD pathogenesis. In some studies TLRs have been identified as susceptibility markers for IBD [1]. Two polymorphic mutations in the extracellular domain of the lipopolysaccharide (LPS) sensor TLR4, Asp299Gly and Thr299Ile, have been shown to be unresponsive to LPS signalling, eliciting an impaired inflammatory response to Gram-negative pathogens and reduced NF- $\mathrm{kB}$ activation [2]. An association study of the TLR4 variant Asp299Gly with IBD in a New Zealand Caucasian population demonstrated a higher carrier frequency of this variant in IBD patients, indicating a role for TLR4 in IBD [1]. However, it has been observed that while polymorphisms may associate with disease, different IBD subgroups can have different genetic backgrounds. Another study of over 6,000 cases of IBD validates the Asp299Gly association, but only in CD [3]. Why this attenuated form of TLR4 might associate with susceptibility to IBD is not clear, but could possibly be due to the role of TLR4 in gut homeostasis, which might be impaired in IBD. A SNP in the gene encoding the protein MaL which is used by TLR4 and TLR2 has also been shown to have a modest effect on IBD susceptibility [3], although again the basis for this association is not understood.

CD14, the first described pattern recognition receptor, is the coreceptor for TLR4 and MD-2 in the detection of bacterial LPS [2]. A study of patients from Western countries found CD14 to be associated with development of $\mathrm{CD}$, yet, there was no observed association with UC [4]. However, a study of chronic UC patients in Japan demonstrated the association of a CD14 variant with increased susceptibility of developing UC [5]. In the same study, while a polymorphism in TLR2 was not shown to be associated with risk of UC, it was associated with steroiddependent patients possibly due to the fact that steroiddependent patients have a hypersensitive response to antigen [5]. Finally, a variant in TLR9 which signals in response to CpG motifs in DNA, Thr1237Cys was shown to be associated with $\mathrm{CD}$ worldwide, however, it was not found to be associated with increased risk of disease in a New Zealand population [6]. The functional role of these variants is not known.

\section{Atherosclerosis}

Atherosclerosis is a chronic inflammatory disease of the arterial blood vessels, caused by formation of plaques resulting in hardening of the arteries. Atherosclerosis is caused by low-density lipoprotein (LDL) cholesterol which enters arteries, where it reacts with oxygen free radicals to form oxidized LDL [7]. Macrophages and T cells respond to this lipoprotein, however, they are unable to process it, resulting in the accumulation of both oxidized LDL as well as macrophages and $\mathrm{T}$ cells in the atherosclerotic plaque [7]. A 5-year study was performed on an Italian population, observing the association of the TLR4 variants Asp299Gly and Thr399Ile with levels of systemic inflammation, risk of bacterial infection and development of atherosclerosis [8]. Reduced levels of the inflammatory cytokine IL- 6 were observed in subjects carrying the Asp299Gly polymorphism only compared to wild-type controls, indicating an impaired inflammatory response and increased risk to bacterial infections. However, soluble adhesion molecules which are important for plaque stability and development of atherosclerosis, and thus are used as biomarkers for the disease, were reduced in subjects carrying TLR4 polymorphisms $[8,9]$. Levels of intercellular cell adhesion molecule 1 (ICAM-1), vascular cell adhesion molecule 1 (VCAM-1) and E-selectin were reduced in subjects harbouring the Asp299Gly polymorphism, indicating a protective effect of this polymorphism in development of atherosclerosis [8]. However, this association is controversial, as a recent study to investigate this potential atheroprotective effect found no difference in the prevalence of this polymorphism in atherosclerotic patients and those without atherosclerosis or the carriage of this polymorphism with disease severity [10].

\section{Asthma}

Asthma is a chronic condition of the respiratory system in which the airway becomes restricted and inflamed. Asthma is caused by a combination of environmental and genetic factors, including exposure to environmental stimulants or allergens, exercise, stress or infection. Symptoms include wheezing, shortness of breath, coughing and chest tightness. The hygiene hypothesis suggests that the occurrence of asthma has increased as levels of hygiene and use of antibiotics have increased, thus reducing exposure to microbial antigen [11]. Indeed, it has been shown that exposure during early life to microbial antigens such as endotoxin significantly reduces development of asthma 
and other allergies [12]. A study of children living on or away from farms in Austria observed a decreased incidence of asthma and allergy when children were exposed to microbial products abundant on farms [13]. While LPS is the main ligand for TLR4, TLR2 has a wide variety of ligands of microbial origin [14]. A study of polymorphism in TLR2 and TLR4 among farmers' and non-farmers' children in Austria and Germany looked for association with incidence of asthma and allergic rhinitis [14]. A polymorphism in TLR2, Thr16934Ala, determines susceptibility of farmers' children to asthma, with these children showing a reduced development of asthma and allergy [14]. In this study there was no association of TLR4 polymorphisms with development of asthma and allergy [14]. A study of young farmers in Germany also saw no association of TLR4 polymorphisms with asthma, allergy and atopy, however, they did observe that enhanced exposure to endotoxin in carriers of TLR4 polymorphisms had a lower incidence of asthma [15]. A study of a Tunisian population observed an association between a TLR9 polymorphism and disease susceptibility, but a study of Japanese population observed no association with this polymorphism $[16,17]$. In the same study of Tunisian people, prevalence of a CD14 variant was significantly higher in the asthmatic group compared to healthy controls [16]. In the past few years, several genetic loci have been implicated in development of asthma, among these, region 12q13-24 has been implicated in asthma aetiology in multiple populations [18]. A recent study performed linkage and association analyses of this region, and identified IRAK-M, an IRAK family member which appears to inhibit TLR signalling and inflammation, as being associated with early-onset persistent asthma [18], although again the functional relevance of this is not known.

\section{Multiple Sclerosis}

Multiple sclerosis (MS) is an autoimmune disorder in which the immune system attacks the central nervous system and impairs signal conduction in affected nerves. This leads to physical and mental symptoms including impaired sensation, movement and cognition. It is thought that MS occurs as a result of a combination of environmental and genetic factors. Various infections can play a role in MS and increased antibody titres to various infectious agents have been detected in MS patients, although there have been inconsistencies between studies. For example, Chlamydia pneumoniae has been associated with MS, with C. pneumoniae DNA being de- tected in $97 \%$ of MS cerebrospinal fluid samples compared to just $18 \%$ of cerebrospinal fluid samples from controls, however, the same trend was not observed in follow-up studies [19]. As already stated, TLR4 signals in response to LPS from various Gram-negative bacteria, including C. pneumoniae. This has led people to investigate the possible link between TLR4 polymorphisms and MS. However, a study of Austrian MS patients found no differences in the incidence of two TLR4 polymorphisms, Asp299Gly and Thr399Ile compared to age-matched disease controls, and presence of this polymorphism did not influence the disease course [20]. As TLR4 mutations are known to influence levels of soluble adhesion molecules, this study analysed levels of E-selectin, soluble VCAM and soluble ICAM-1 in MS, but found no differences for both TLR4 polymorphisms [20]. A study of a German population of MS patients also found no significant role for Asp299Gly polymorphism in disease susceptibility or severity [21]. A further study of 12 different polymorphisms in TLR4 found no association for any polymorphism with MS in a Spanish population [22]. From these studies it is clear that TLR4 appears to play no major role in susceptibility to MS or disease outcome. However, a recent study using a mouse model of myelin oligodendrocyte glycoprotein-induced experimental autoimmune encephalomyelitis, the animal model for MS, demonstrated a role for both TLR4 and TLR9 in regulation of MS severity [23]. Splenic myeloid dendritic cells (mDC) from TLR4-deficient mice produced higher levels of IL-6 and IL-23 than mDCs from wild-type mice. mDCs from TLR9-deficient mice also produced higher levels of IL- 6 compared to wild-type mDCs. Both TLR4- and TLR9deficient mice developed more severe experimental autoimmune encephalomyelitis, indicating that their signalling cascades regulate severity of the disease. However, the exact mechanism is not known.

\section{Rheumatoid Arthritis}

Rheumatoid arthritis (RA) is a chronic, inflammatory autoimmune disorder in which the immune system attacks the joints, leading to severe pain and loss of mobility. The expression of TLR2 and TLR4 was analysed in synovial tissue from RA patients [24]. Both TLR2 and TLR4 were expressed in synovial tissue of patients with active disease compared to tissue from healthy controls, and this expression was associated with IL-12 and IL-18 levels. In a study of RA patients, the TLR4 variant Asp299Gly was more prevalent in healthy individuals com- 
pared to those with disease, indicating an association with reduced RA susceptibility [24], possibly because this is an attenuating mutation that would therefore be less inflammatory. However, earlier studies found no significant difference between RA patients and healthy controls for carriage of TLR2 (Arg677Trp and Arg753Gln) and TLR4 (Asp299Gly and Thr399Ile) variants [25, 26]. No association has been found with a MaL variant, MaL Ser180Leu, which associates with infectious diseases and systemic lupus erythematosus (SLE; see below) in over 900 cases of RA [27].

\section{Systemic Lupus Erythematosus}

SLE, more commonly referred to as lupus, is a chronic autoimmune disease which can affect many parts of the body including heart, lungs, liver, kidneys, blood vessels, skin, joints and nervous system. There are a number of factors proposed to trigger lupus, including environmental factors such as certain medications, drugs, ultraviolet light and viruses as well as genetic factors. Lupus appears to run in families and mainly affects women, especially those of African-American descent. Increased serum levels of IFN- $\alpha$ and chronically activated plasmacytoid dendritic cells are characteristic of SLE patients [28]. The most efficient inducers of IFN- $\alpha$ production by plasmacytoid dendritic cells are synthetic ligands for TLR7 and TLR9 as well as DNA and RNA viruses. As a result, TLR9 and TLR7 may be important to the development of the disease. Autoimmunity against chromatin is a feature of SLE, and TLR9 is thought to play a role in the production of these autoantibodies [29]. Indeed, production of antichromatin autoantibodies is inhibited in TLR9-deficient lupus-prone mice [30]. Inhibition of TLR9 and TLR7 attenuates lung injury in experimental lupus, offering potential targets for therapeutic use [31, 32]. However, studies have found no association between TLR9 polymorphisms and susceptibility to SLE [32]. Similarly, there is no evidence for association of TLR2, TLR4 and TLR5 gene polymorphisms in SLE $[26,33]$. Recently, however, MaL Ser180Leu has been found to associate with SLE and is a protective factor against this disease [34]. Heterozygous carriage of this variant, which is predicted to show a modulated response to ligands, associates with a 5-fold decreased risk of SLE. MaL Leu180 has been shown to be functionally impaired, since unlike MaL Ser180 it fails to restore signalling in MaL-deficient cells [35]. Evidence has also been presented for MaL Leu180 having a dominant negative effect against MaL Ser180. These data sug- gest that MaL Ser180 homozygotes will have a stronger response to TLR2 (or TLR4) activation than either heterozygotes or MaL Leu180 homozygotes. This might be why MaL Ser180 homozygotes are more prone to SLE and also various infectious diseases (see below). It is possible that an exacerbated response to pathogens initiated by TLR2 and TLR4 may potentiate SLE attacks.

\section{Bacterial Infections/Sepsis}

More than half of cases of sepsis are caused by infection with Gram-negative bacteria [36]. As a result, there has been much interest in the role of TLR4 and sepsis. TLR4 polymorphisms have been shown to increase the risk of Gram-negative infections and sepsis [37]. However, an association study in Korean patients with bacteremia detected no genetic polymorphisms for TLR4 and TLR2 in both bacteremic patients and healthy controls [38]. A study of Caucasian patients with sepsis due to polymicrobial infection also found no functional effect of the TLR4 polymorphism Asp299Gly and, furthermore, the TLR4 mutation did not alter development of sepsis in a murine model [39].

While there is no apparent link between TLR polymorphisms and sepsis, there have been associations with some infections. Malaria is an infectious disease caused by protozoan parasites of the genus Plasmodium and is transmitted by mosquitoes. Innate immune recognition and subsequent clearance of Plasmodium infection may contribute to disease severity [40]. As a result, the role of TLRs and malaria has been investigated. A study of African children with malaria investigated the effect of polymorphisms in TLR2, TLR4 and TLR9 on severity of disease [41]. In this study, there was no association with TLR2 and TLR9 polymorphisms and disease. However, the TLR4 polymorphisms Asp299Gly and Thr399lle were more frequent in malaria cases and conferred increase risks of severe malaria [41]. A study of Plasmodium falciparum-infected African women observed a role for TLR4 Asp299Gly and TLR9 Thr1486Cys polymorphisms with the clinical manifestation of malaria during pregnancy, including foetal growth restriction and maternal anaemia [41]. A recent study, genotyping the MaL Ser180Leu variant in 3 populations with malaria from Gambia, Kenya and Vietnam, found that this variant provided a protection against disease, with heterozygotes being more prevalent in healthy controls [35].

Tuberculosis (TB) is an airborne infectious disease caused by Mycobacterium which mainly affects the lungs 
but can also affect other parts of the body. TB is most prevalent in developing countries. TLRs are involved in the recognition of mycobacterial cell wall components and TLR 2 as well as TLR4 play a role in the development of innate responses $[42,43]$. A study of the Arg753Gln polymorphism in TLR2 found that this polymorphism is associated with risk of TB in Turkish patients [44]. This polymorphism was more frequently observed in TB patients compared to healthy controls. Furthermore, the risk of developing TB was increased 6.04-fold in carriers. A study of Gambian TB patients found no association between disease and presence of the TLR4 polymorphism Asp299Gly, and this variant had no effect on LPS responsiveness of monocytes [45]. In a recent study, whole genome-wide sequencing of coding regions for 5 TLRs (TLR1, TLR2, TLR4, TLR6 and TLR10) was performed on African-American, European-American and Hispanic TB patients and healthy controls [46]. In this study, the frequency of variants was increased among TB patients and in particular, there was a significant association among African-American TB patients, correlating with the fact that TB is most common in African countries. Variants in TLR6 were significantly associated with TB patients and, interestingly, TLR6 is important for clearance of Mycobacterium as it dimerizes with TLR2 to activate macrophages, an important step towards clearance of the infection $[47,48]$.

Recent studies have found associations with the MaL Ser180Leu variant and protection from tuberculosis, although this has not been replicated in any studies $[34,35$, $49,50]$. There have also been several reports linking IL-1 receptor adaptor kinase (IRAK) 4 variants to disease [51]. IRAK4 is used by all TLRs except TLR3 to signal to NF$\kappa \mathrm{B}$. An inherited IRAK4 deficiency in humans has been reported which leads to recurrent pyogenic bacterial infections and invasive pneumococcal disease [51]. A recent study was performed on IRAK4-deficient patients from 11 different countries exposed to potential viral, fungal and bacterial pathogens and parasites [51]. Most patients suffered from invasive pneumococcal disease caused by Streptococcus pneumoniae and some with Staphylococcus aureus infection. Almost half of the patients died, with no death occurring in patients older than 8 years. Also, there was no invasive infection in patients older than 14 years. These results suggest that IRAK4 is vital for childhood immunity to pyogenic infection.

There are reports of association of TLR variants with other bacterial infections. Ile602Ser is a common SNP in TLR1, associated with reduced incidence of leprosy, a chronic infectious disease caused by the bacterium $M y$ - cobacterium leprae [52]. A study of children with urinary tract infections found an association of the TLR2 Arg$753 \mathrm{Gln}$ polymorphism with the patient group [53]. The TLR5 stop codon polymorphism, Arg393STOP has been associated with susceptibility to Legionnaires disease, a severe infectious disease caused by bacteria of the genus Legionella [50].

\section{Gastritis, Gastric Cancer and Prostate Cancer}

Gastritis is an inflammation of the gastric mucosa caused by many possible factors, including infection, most commonly by Helicobacter pylori [54]. This can develop further into gastric cancer. TLR2 and TLR4 have been shown to be important for recognition of $H$. pylori in neutrophils, resulting in production of IL-8 and IL-10 [55]. The TLR4 variant Asp299Gly was found to be present at similar rates in patients with a risk of gastritis and healthy controls [56]. However, the TLR4 variant Thr399Ile was detected at an increased rate in patients, and carriers had an increased level of plasma cell infiltration and development of precancerous lesions [56]. Thus, TLR4 Thr399Ile plays a possible role in the development of gastritis and gastric cancer. A TLR4 Ala896Gly variant has also been associated with gastric carcinoma [57]. A study of a Japanese population of $H$. pylori-induced gastritis and gastric ulcers found no association of a TLR2 variant which causes a 22 -bp deletion, -196 to -171 del, with development of gastric ulcer, duodenal ulcer, gastric and duodenal ulcer and gastritis [58]. However, this variant was associated with risk of severe intestinal metaplasia in older and in female subjects.

Prostate cancer develops as a result of chronic inflammation and either exposure to infectious agents or dietary agents or as a result of hormone imbalance [54]. Genetic susceptibility is a major risk factor for this disease. Several TLR variants have been associated with risk of prostate cancer, including TLR4 and the TLR1-6-10 gene cluster [54,59]. A genetic analysis of TLR4 variants in newly diagnosed Swedish prostate cancer patients and healthy controls found that of all variants analysed, one in the 3'-UTR of the TLR4 gene, Gly11381Cys, was associated with a $26 \%$ increased risk of prostate cancer and a $39 \%$ increased risk of being diagnosed with prostate cancer before age 65 [59]. However, in a follow-up study of American men diagnosed with prostate cancer between 1993 and 2000, no association with this TLR4 polymorphism was observed [60]. Another study of prostate patients carried out by Cancer Prostate in Sweden observed 
associations between sequence variants of the TLR6TLR1-TLR10 gene cluster and the risk of prostate cancer [61]. However, a similar study among American prostate patients found no association between sequence variants of this gene cluster and risk of prostate cancer [62].

\section{Conclusion}

Many studies have now been performed attempting to link genetic variation in TLRs and some of their signals with susceptibility to infectious and inflammatory diseases. The best examples so far are a link between TLR4 Asp299Gly and sepsis, IBD and asthma. Associations between SNPs in IRAK-M and asthma have also been reported, but also between MaL and malaria as well as between TB and SLE. Finally, a clear role for IRAK4 in the response to staphylococcal infections in childhood has been reported. Ongoing studies will hopefully clarify the role of genetic variation and disease susceptibility in this important class of innate receptors. Whether there are associations or not, it is clear that TLRs remain attractive therapeutic targets for infectious and inflammatory diseases.

\section{Acknowledgements}

Research in the author's laboratory is supported by grants from Science Foundation Ireland and the Irish Health Research Board.

\section{References}

1 Browning BL, Huebner C, Petermann I, Gearry RB, Barclay ML, Shelling AN, Ferguson LR: Has Toll-like receptor 4 been prematurely dismissed as an inflammatory bowel disease gene? Association study combined with meta-analysis shows strong evidence for association. Am J Gastroenterol 2007; 102:2504-2512.

$\checkmark 2$ Rallabhandi P, Bell J, Boukhvalova MS, Medvedev A, Lorenz E, Arditi M, Hemming VG et al: Analysis of TLR4 polymorphic variants: new insights into TLR4/MD2/CD14 stoichiometry, structure and signalling. J Immunol 2006;177:322-332.

3 De Jager PL, Franchimont D, Waliszewska A, Bitton A, Cohen A, Langelier D, Belaiche J, et al: The role of the Toll receptor pathway in susceptibility to inflammatory bowel diseases. Genes Immun 2007;8:387-397.

4 Gazuoli M, Mantzaris, G, Kotsinas, A, Zacharatos P, Papalambros E, Archimandritis A, Ikonomopoulos J, et al: Association between polymorphisms in the Toll-like receptor 4, CD14, and CARD15/NOD2 and inflammatory bowel disease in the Greek population. World J Gastroenterol 2005;11: 681-685.

5 Wang F, Tahara, T, Arisawa T, Shibata T, Nakamura M, Fujita H, Iwata M, et al: Genetic polymorphisms of CD14 and Toll-like receptor-2 (TLR2) in patients with ulcerative colitis. J Gastroenterol Hepatol 2007;22:925929.

- 6 Hong J, Leung E, Fraser AG, Merriman TR, Vishnu P, Krissansen GW: TLR2, TLR4, TLR9 polymorphisms and Crohn's disease in a New Zealand Caucasian population. J Gastroenterol Hepatol 2007;22:1760-1766.

7 Kunitomo M: Oxidative stress and Atherosclerosis. Yakugaku Zasshi 2007;127:19972014.
8 Kiechl S, Lorenz E, Reindl M, Wiedermann CJ, Oberhollenzer F, Bonora E, Willeit J, Schwartz DA: Toll-like receptor 4 polymorphisms and atherogenesis. N Engl J Med 2002;347:185-192.

-9 Ballantyne CM, Entman ML: Soluble adhesion molecules and the search for biomarkers for atherosclerosis. Circulation 2002;106: 766-767.

10 Hommels MJ, Kroon AA, Netea MG, De Leeuw PW, Bruggemann CA, Leiner T, Koster DA, et al: The Asp299Gly Toll-like receptor 4 polymorphism in advanced aortic artherosclerosis. Neth J Med 2007;65:203207.

$\checkmark 11$ Beisswenger C, Bals R: Interaction of allergies airway inflammation and innate immunity: hygiene and beyond. J Occup Med Toxicol 2008;3(suppl 1):S3.

12 Von Mutius E, Braun-Fahrlander C, Schierl R, Riedler J, Ehlermann S, Maisch S, Waser M, Nowak D: Exposure to endotoxin or other bacterial components might protect gainst the development of atopy. Clin Exp Allergy 2000;30:1230-1234

-13 Riedler J, Braun-Fahrlander C, Eder W, Schreuer M, Waser M, Maisch S, Carr D, Schierl R, et al: Exposure to farming in early life and development of asthma and allergy: a cross-sectional survey. Lancet 2001;358: 1129-1133.

$\checkmark 14$ Eder W, Klimecki W, Yu L, Von Mutius E, Riedler J, Braun-Fahrlander C, Nowak D, et al: Toll-like receptor 2 as a major gene for asthma in children of European farmers. J Allergy Clin Immunol 2004;113:482-488.

15 Werner M, Topp R, Wimmer K, Richter K, Bischof W, Wjst M, Heinrich J: TLR4 gene variants modify endotoxin effects on asthma. J Allergy Clin Immunol 2003;112:323330.
16 Lachheb J, Dhifallah IB, Chelbi H, Hamzaoui K, Hamzaoui A: Toll-like receptors and CD14 genes polymorphisms and susceptibility to asthma in Tunisian children. Tissue Antigens 2008;71:417-425.

-17 Noguchi E, Nishimura F, Fukai H, Kim J, Ichikawa K, Shibasaki M, Arinami T: An association study of asthma and total serum immunoglobin E levels for Toll-like receptor polymorphisms in a Japanese population. Clin Exp Allergy 2004;34:177-183.

18 Balaci L, Spada MC, Olla N, Sole G, Loddo L, Anedda F, Naitza S, et al: IRAK-M is involved in the pathogenesis of early-onset persistant asthma. Am J Hum Genet 2007; 80:1103-1114.

19 Reindl M, Lutterotti A, Ingram J, Schanda K, Gassner C, Deisenhammer F, Berger T, Lorenz E: Mutations in the gene for toll-like receptor 4 and multiple sclerosis. Tissue Antigens 2003;61:85-88.

20 Kroner A, Vogel F, Kolb-Maurer A, Kruse N, Toyka KV, Hemmer B, Rieckmann P, Maurer M: Impact of the Asp299Gly polymorphism in the toll-like receptor 4 (tlr4) gene on disease course of multiple sclerosis. J Neuroimmunol 2005;165:161-165.

21 Urcelay E, Blanco-Kelly F, De las Heras V, De la Concha EG, Arroya R, Martinez A: TLR4 haplotypes in multiple sclerosis: a case-control study in the Spanish population. J Neuroimmunol 2007;192:215-218.

22 Marta M, Andersson A, Isaksson M, Kampe O, Lobell A: Unexpected regulatory roles of TLR4 and TLR9 in experimental autoimmune encephalomyelitis. Eur J Immunol 2008:38:565-575. 
-23 Radstake TR, Franke B, Hanssen S, Netea MG, Welsing P, Barrera P, Joosten PA, et al: The Toll-like receptor 4 Asp299Gly functional variant is associated with decreased rheumatoid arthritis disease susceptibility but does not influence disease severity and/or outcome. Arthritis Rheum 2004;50:999-1007.

-24 Kilding R, Akil M, Till S, Amos R, Winfield J, Iles MM, Wilson AG: A biologically important single nucleotide polymorphism within the toll-like receptor-4 gene is not associated with rheumatoid arthritis. Clin Exp Rheumatol 2003;21:340-342.

-25 Sanchez E, Orozco G, Lopez-Nevot MA, Jimenez-Alonso J, Martin J: Polymorphisms of toll-like receptor 2 and 4 genes in rheumatoid arthritis and systemic lupus erythematosus. Tissue Antigens 2004;63:54-57.

-26 Barrat FJ, Meeker T, Gregorio J, Chan JH, Uematsu S, Akira S, Chang B, et al: Nucleic acids of mammalian origin can act as endogenous ligands for Toll-like receptors and may promote systemic lupus erythematosus. J Expt Med 2005;202:1131-1139.

-27 Sheedy FJ, Marinou I, O’Neill LA, Wilson AG: The Mal/TIRAP S180L and TLR4 G299D polymorphisms are not associated with susceptibility to or severity of rheumatoid arthritis. Ann Rheum Dis 2008;67:1328-1331.

-28 Anders HJ: A Toll for lupus. Lupus 2005;14: 417-422.

-29 Christensen SR, Kashgarian M, Alexopoulou L, Flavell RA, Akira S, Shlomchik MJ: Toll-like receptor 9 controls anti-DNA autoantibody production in murine lupus. J Exp Med 2005;202:321-331.

30 Lenert PS: Targeting Toll-like receptor signalling in plasmacytoid dendritic cells and autoreactive B cells as a therapy for lupus. Arthritis Res Ther 2006;8:203.

-31 Bhattacharjee RN, Akira S: Modifying tolllike receptor 9 signalling for therapeutic use. Mini Rev Med Chem 2006;6:287-291.

\32 Hur JW, Shin HD, Park BL, Kim LH, Kim SY, Bae SC: Association study of Toll-like receptor 9 gene polymorphisms in Korean patients with systemic lupus erythematosus. Tissue Antigens 2005;65:266-270.

-33 Demirci FY, Manzi S, Ramsey-Goldman R, Kenney M, Shaw PS, Dunlop-Thomas CM, $\mathrm{Kao} \mathrm{AH}$, et al: Association study of Toll-like receptor 5 (TLR5) and Toll-like receptor 9 (TLR9) polymorphisms in systemic lupus erythematosus. J Rheumatol 2007;34:17081711.

-34 Castiblanco J, Varela DC, Castano-Rodriquez N, Rojas-Villarraga A, Hincapie ME, Anaya JM: TIRAP (MAL) S180L polymorphism is a common protective factor against developing tuberculosis and systemic lupus erythematosus. Infect Genet Evol 2008;8: 541-544.

-35 Khor CC, Chapman SJ, Vannberg FO, Dunne A, Murphy C, Ling EY, Frodsham AJ, et al: A $\mathrm{Mal}$ functional variant is associated with protection against invasive pneumococcal disease, bacteremia, malaria and tuberculosis. Nat Genet 2007;39:523-528.
36 Martin GS, Mannino DM, Eaton S, Moss M: The epidemiology of sepsis in the United States from 1979 through 2000. N Engl J Med 2003;348:1546-1554.

-37 Lorenz E, Mira J, Frees K, Schwartz D: Relevance of mutations in the TLR4 receptor in patients with Gram negative septic shock. Arch Int Med 2002;162:1028-1032.

38 Yoon HJ, Choi JY, Kim CO, Park YS, Kim MS, Kim YK, Shin SY, et al: Lack of toll-like receptor 4 and 2 polymorphisms in Korean patients with bacteremia. J Korean Med Sci 2006;21:979-982.

39 Feterowski C, Emmanuilidis K, Miethke T, Gerauer K, Rump M, Ulm K, Holzmann B, Weighardt $\mathrm{H}$ : Effects of functional toll-like receptor- 4 mutations on the immune response to human and experimental sepsis. Immunology 2003;109:426-431.

40 Stevenson MM, Riley EM: Innate immunity to malaria. Nat Rev Immunol 2004;4:169-180.

-41 Mockenhaupt FP, Cramer JP, Hamann L, Stegemann MS, Eckert J, Oh NR, Otchwemah RN, Dietz E, et al: Toll-like receptor (TLR) polymorphisms in African children: common TLR4 variants predispose to severe malaria. Proc Natl Acad Sci USA 2006;103:177-182.

42 Centers for Disease Control: Fact Sheet: Tuberculosis in the United States. Atlanta, Centers for Disease Control, 2005.

43 Quesniaux V, Fremond C, Jacobs M, Parida S, Nicolle D, Yeremeev V, Bihl F, et al: Tolllike receptor pathways in the immune responses to mycobacteria. Microbes Infect 2004;6:946-959.

44 Ferwerda G, Kullberg BJ, de Jong DJ, Girardin SE, Langenberg DM, van Crevel R, Ottenhoff $\mathrm{TH}$, et al: Mycobacterium paratuberculosis is recognised by Toll-like receptors and NOD2. J Leukoc Biol 2007;82:1011-1018.

45 Ogus AC, Yoldas B, Ozdemir T, Uguz A, Olcen S, Keser I, Coskun M, et al: The Arg$753 \mathrm{Gln}$ polymorphism of the human Tolllike receptor 2 gene in tuberculosis disease. Eur Respir J 2004;23:219-223.

46 Newport MJ, Allen A, Awomoyi AA, Dunstan SJ, McKinney E, Marchant A, Sirugo G: The toll-like receptor 4 Asp299Gly variant: no influence on LPS responsiveness or susceptibility to pulmonary tuberculosis in the Gambia. Tuberculosis 2004;84:347-352.

47 Ma X, Liu Y, Gowen BB, Graviss EA, Clark AG, Musser JM: Full-exon resequencing reveals toll-like receptor variants contribute to human susceptibility to tuberculosis disease. PLoS ONE 2007;2:e1318.

48 Ozinsky A, Underhill DM, Fontenot JD, Hajjar AM, Smith KD, Wilson CB, Schroeder L, Aderem A: The repertoire of pattern recognition of pathogens by the innate immune system is defined by cooperation between toll-like receptors. Proc Natl Acad Sci USA 2000;97:13766-13771.

49 Nejentsev S, Thye T, Szeszko JS, Stevens H, Balabanova Y, Chinbuah AM, Hibberd M, et al: Analysis of association of the TIRAP (MAL) S180L variant and tuberculosis in three populations. Nat Genet 2008;40:261-262.
50 Hawn TR, Verbon A, Lettinga KD, Zhao LP, Li SS, Laws RJ, Skerrett SJ, et al: A common dominant TLR5 stop codon polymorphism abolishes flagellin signalling and is associated with susceptibility to Legionnaires disease. J Exp Med 2003;198:1563-1572.

51 Picard C, Von Bernuth H, Ku CL, Yang K, Puel A, Casanova JL: Inherited human IRAK-4 deficiency: an update. Immunol Res 2007;38:347-352.

52 Johnson CM, Lyle EA, Omueti KO, Stepensky VA, Yegin O, Alpsoy E, Hamann L, et al: Cutting edge: a common polymorphism impairs cell surface trafficking and functional responses of TLR1 but protects against leprosy. J Immunol 2007;178:7520-7524.

53 Tabel Y, Berdeli A, Mir S: Association of TLR2 gene Arg753Gln polymorphism with urinary tract infection in children. Int J Immunogenet 2007;34:399-405.

54 El-Omar EM, Ng Mt, Hold GL: Polymorphisms in toll-like receptor genes and risk of cancer. Oncogene 2008;27:244-252.

55 Alvarez-Arellano L, Camorlinga-Ponce M, Maldonado-Bernal C, Torres J: Activation of human neutrophils by Helicobacter pylori and the role of toll-like receptors 2 and 4 in the response. FEMS Immunol Med Microbiol 2007;51:473-479.

56 Achyut BR, Goshal UC, Moorchung N, Mittal B: Association of Toll-like receptor 4 (Asp299Gly and Thr399Ileu) gene polymorphisms with gastritis and precancerous lesions. Hum Immunol 2007;68:901-907.

57 Hold GL, Rabkin CS, Chow WH, Smith MG, Gammon MD, Risch HA, Vaughan TL, et al: A functional polymorphism of toll-like receptor 4 gene increases risk of gastric carcinoma and its precursors. Gastroenterology 2007;132:905-912.

58 Tahara T, Arisawa T, Wang F, Shibata T, Nakamura M, Sakata M, Hirata I, Nakano H: Toll-like receptor 2 (TLR)-196 to $174 \mathrm{del}$ polymorphism in gastro-duodenal diseases in Japanese population. Dig Dis Sci 2008;53: 919-924.

59 Zheng SL, Augustsson-Balter K, Chang B, Hedelin M, Li L, Adami HO, Bensen J, Li G, Johnasson JE, et al: Sequence variants of Toll-like receptor 4 are associated with prostate cancer risk: results from the cancer prostate in Sweden study. Cancer Res 2004;64: 2918-2922.

-60 Chen YC, Giovannucci E, Lazarus R, Kraft P, Ketkar S, Hunter DJ: Sequence variants of toll-like receptor 4 and susceptibility to prostate cancer. Cancer Res 2005;65:1177111778.

61 Sun J, Wikland F, Zheng LS, Chang B, Balter $\mathrm{K}, \mathrm{Li} \mathrm{L}$, Johansson JE, et al: Sequence variants in toll-like receptor gene cluster (TLR6TLR1-TLR10) and prostate cancer risk. J Natl Cancer Inst 2007;97:525-532.

62 Chen YC, Giovannucci E, Kraft P, Lazarus R, Hunter DJ: Association between Toll-like receptor gene cluster (TLR6, TLR1, and TLR10) and prostate cancer. Cancer Epidemiol Biomarkers Prev 2007;16:1982-1989. 